\title{
PQQ-Aza-Crown Ether Complexes as Biomimetics for Lanthanide and Calcium Dependent Alcohol Dehydrogenases
}

Violeta A. Vetsova, ${ }^{a}$ Katherine R. Fisher, ${ }^{a}$ Henning Lumpe, ${ }^{a}$ Alexander Schäfer, ${ }^{b}$ Erik K. Schneider, Patrick Weis ${ }^{b}$ and Lena J. Daumann ${ }^{a, *}$

aLudwig-Maximilians-Universität München, Department Chemie, Butenandtstr. 5-13, 81377 München*lena.daumann@Imu.de

${ }^{\text {b} K a r l s r u h e r ~ I n s t i t u t ~ f u ̈ r ~ T e c h n o l o g i e, ~ I n s t i t u t ~ f u ̈ r ~ P h y s i k a l i s c h e ~ C h e m i e, ~ F r i t z-H a b e r-W e g ~ 2, ~} 76128$ Karlsruhe

\begin{abstract}
Understanding the role of metal ions in biology can lead to the development of new catalysts for several industrially important transformations. Lanthanides are the most recent group of metal ions that have been shown to be important in biology i.e. - in quinone-dependent methanol dehydrogenases (MDH). Here we evaluate a pyrroloquinoline quinone and 1-aza-15-crown-5 based ligand platform as scaffold for $\mathrm{Ca}^{2+}, \mathrm{Ba}^{2+}, \mathrm{La}^{3+}$ and $\mathrm{Lu}^{3+}$ biomimetics of $\mathrm{MDH}$ and we evaluate the importance of ligand design, charge, size, counterions and base for the alcohol oxidation reaction using NMR spectroscopy. In addition, we report a new straightforward synthetic route (3 steps instead of 11 and $33 \%$ instead of $0.6 \%$ yield) for biomimetic ligands based on PQQ. We show that when studying biomimetics for $\mathrm{MDH}$, larger metal ions and those with lower charge in this case promote the dehydrogenation reaction more effectively and that this is likely an effect of the ligand design which must be considered when studying biomimetics. To gain more information on the structures and impact of counterions of the complexes, we performed collision induced dissociation (CID) experiments and observe that the nitrates are more tightly bound than the triflates. To resolve the structure of the complexes in the gas phase we combined DFT-calculations and ion mobility measurements (IMS). Furthermore, we characterized the obtained complexes and reaction mixtures using Electron Paramagnetic Resonance (EPR) spectroscopy and show the emergence of a quinonebased radical during the reaction with substrate and base.
\end{abstract}

\section{Introduction}

Despite having low abundance in organisms compared to bulk elements such as $\mathrm{C}, \mathrm{H}, \mathrm{N}$ and $\mathrm{O}$, metals play an important and irreplaceable role in metabolic processes. ${ }^{[1]}$ The latest group of elements that have shown to be biologically relevant are the lanthanides (Ln). Recent discoveries show their widespread utilization in the methanol metabolism of methylotrophic and methanotrophic bacteria. ${ }^{[2-6]}$ In these bacteria, methanol dehydrogenase (MDH) enzymes catalyze the oxidation of methanol to formaldehyde. Two very similar pyrroloquinoline quinone (PQQ) dependent $M D H$ enzymes exist in nature (Figure 1): one bearing a calcium ion in the active site (MxaF-type, Ca-MDH) 
and the other class utilize early lanthanides (XoxF-type, Ln-MDH). It has been suggested that Ln-MDH is evolutionary older, catalytically superior and more prevalent in nature. ${ }^{[7]}$

A

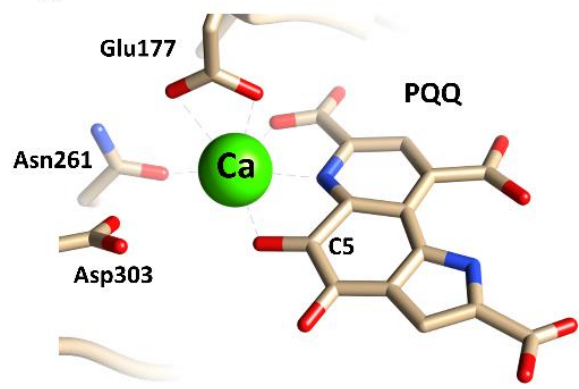

B

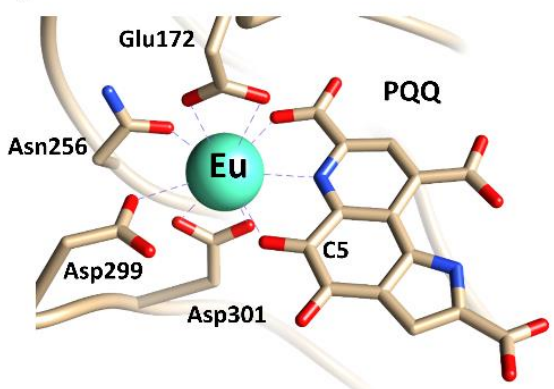

Figure 1: The active sites of (A) MxaF-MDH (PDB: 1H4I) and (B) XoxF-MDH (PDB: 6FKW). Images generated with the UCSF Chimera package. ${ }^{[8]}$

To broaden the knowledge of XoxF- and MxaF-type MDH enzymes, the synthesis of several model complexes was described in the literature, mimicking the structure or function of the active sites. Itoh and Fukuzumi investigated the Ca-dependent MxaF-type MDH by synthesizing ligand PQQMe $\mathrm{P}_{2}-1-$ aza-15-crown-5 (1) through coupling of the total synthesis PQQ precursor (2) with an aza-crown ether (Chart 1). ${ }^{[9]}$ Drawbacks include the multi-step synthesis to $\mathbf{2}$ and a low overall yield for the synthesis of $\mathbf{1}$ ( $0.6 \%$ over eleven steps in total).<smiles>O=C(O)c1cc(C(=O)O)c2c(n1)C(=O)C(=O)c1cc(C(=O)O)[nH]c1-2</smiles>

$P Q Q$

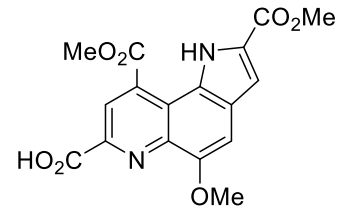

2

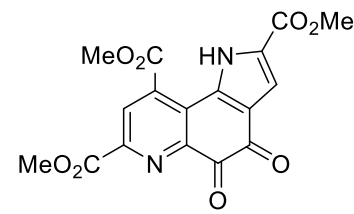

3<smiles></smiles>

4

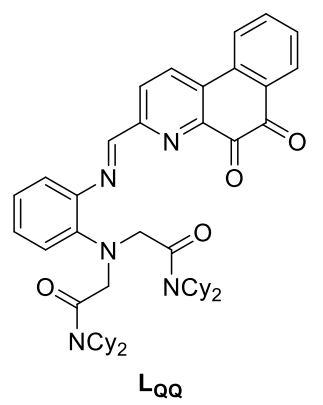

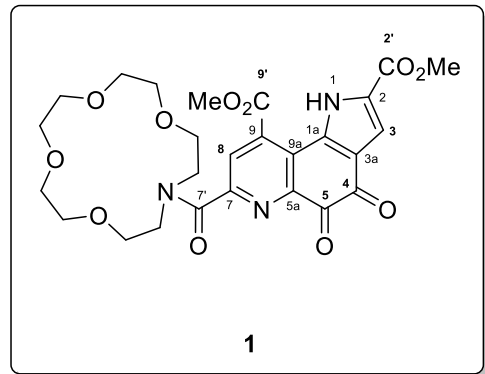

Chart 1: Ligands and precursors discussed in this study. Numbering scheme of the PQQ-moiety in 1 according to Unkefer et al.[10]

The crown ether oxygen atoms somewhat mimic the amino acid donor atoms of the MDH active site and coordinate $\mathrm{Ca}^{2+}$ in addition to PQQ. Itoh and Fukuzumi reported larger binding constants of 1 with alkaline earth elements $\left(210000 \mathrm{M}^{-1}\right.$ for $\left.\mathrm{Ca}^{2+}\right)$ in comparison to $\mathrm{PQQMe}_{3}$ (3) $\left(1900 \mathrm{M}^{-1}\right.$ for $\left.\mathrm{Ca}^{2+}\right)$. Furthermore, an UV-Vis investigation suggested that coordinated $\mathrm{Ca}^{2+}$ enhances EtOH addition to $\mathbf{1}$, as the equilibrium constant is six times higher $\left(1.2 \mathrm{M}^{-1}\right)$ than without $\mathrm{Ca}^{2+}\left(0.2 \mathrm{M}^{-1}\right)$. By addition of the strong base DBU to an ethanol containing solution of $[\mathrm{Ca}(\mathbf{1})]^{2+}$, the quinone $\left[\mathrm{Ca}\left(\mathbf{1}_{\mathrm{OEt}}\right)\right]^{2+}$ is reduced to the corresponding quinol $\left[\mathrm{Ca}\left(\mathbf{1 H}_{2}\right)\right]^{2+}$, concurrent to acetaldehyde formation by oxidation of ethanol. The rate constant of the ethanol oxidation is almost the same for $[\mathrm{Ca}(\mathbf{1})]^{2+}\left(1.7 \mathrm{M}^{-1} \mathrm{~s}^{-1}\right)$ in comparison 
to $[\mathrm{Ca}(3)]^{2+}\left(2.1 \mathrm{M}^{-1} \mathrm{~s}^{-1}\right)$. The larger alkaline earth elements revealed slightly reduced alcohol addition for $\mathrm{Ba}^{2+}$ but enhanced oxidation rates. An addition elimination mechanism was proposed by the authors (Figure S1).

The first model complex for Ln-dependent alcohol dehydrogenases was synthesized by Schelter et al., ${ }^{[11]}$ by coupling a PQQ-inspired quinone with tetracyclohexyl-3-(2-aminophenyl)pentanediamide in the final step yielding ligand $\mathrm{LQQ}_{\mathrm{QQ}}$. The authors demonstrated $\mathrm{La}^{3+}$ coordination to $\mathrm{L}_{\mathrm{QQ}}$ and provided a crystal structure for the resulting complex $\left[\mathrm{La}(\mathrm{LQQ})\left(\mathrm{NO}_{3}\right)_{3}\right]$ with three nitrate equivalents as counter ions. Cyclic voltammograms revealed the quinone/semiquinone reversible couple at $\mathrm{E}_{1 / 2}=-0.95 \mathrm{~V}$ for $\mathrm{L}_{\mathrm{QQ}}$, which was shifted to higher potentials upon $\mathrm{La}^{3+}$ coordination $\left(\mathrm{E}_{1 / 2}=-0.34 \mathrm{~V}\right)$ by stabilizing the semiquinone state. Through $\mathrm{La}^{3+}$ coordination, oxidation of 4-methyl benzyl alcohol to the respective aldehyde was demonstrated, and this process was accelerated by addition of either 2,6-lutidine or DBU. Using DFT, the authors calculated both, the hemiketal and hydride transfer mechanism pathways for the dehydrogenation reaction of the model. Hydride transfer was clearly favored with either a weak base (2,6-lutidine) or without a base (Figure S1). Addition of DBU drastically reduced the energy barrier for the hemiketal aldehyde elimination from 32.7 to $14.8 \mathrm{kcal} \mathrm{mol}^{-1}$ making this mechanism energetically possible. However, the barrier was still slightly higher than for the hydride transfer $\left(9 \mathrm{kcal} \mathrm{mol}^{-1}\right)$.

Recently Luo et al. showed that the semiquinone-lanthanum complex $\left[\mathrm{La}(\mathbf{O}-\mathbf{Q})_{2}\right]$ can also serve as an efficient catalyst for the oxidation of alcohols under aerobic conditions. ${ }^{[12]}$ The catalysis was initialized by reduction via single electron transfer of the ortho-quinone ligand $\boldsymbol{o}-\mathbf{Q}$ after coordinating with $\mathrm{Lal}_{3}$. A screening of different conditions showed that the addition of a base did not have an obvious effect on the reaction outcome. However, a significant kinetic isotope effect was observed on $\mathrm{O}-\mathrm{H}$ and $\mathrm{C}-\mathrm{H}$ of benzylic alcohol. Based on this and further experimental observations, the authors proposed a coupled proton-hydride transfer mechanism instead of stepwise deprotonation and hydride transfer for the oxidation of alcohols in their preprint (Figure S1). In addition, a Lewis acid screening showed that all lanthanide triflates were able to catalyze the reaction. However, no trend in terms of achieved yields could be observed across the lanthanide series, since the highest yields were calculated for La (89\%), Yb (80\%) and Lu (72\%), whereas some members of the early lanthanides like $\mathrm{Ce}$ and $\mathrm{Nd}$ showed lower yields of $44 \%$. Moreover, the experiment performed with calcium triflate showed no substrate conversion at all. Given the fact that the pyridine (and pyrrole) moiety is lacking in ligand $\boldsymbol{o - Q}$ and the coordination of $L n$ is taking place at both quinone oxygens, the system cannot be considered a true MDH biomimetic. Nevertheless, the study presents an interesting use of both quinones and lanthanides in alcohol oxidation reaction and together with previous studies on different PQQ surrogates it further underlines the importance of the cofactor structure for the processes taking place in the active site of the enzyme. ${ }^{[13]}$

Hence, so far only MDH biomimetics containing either alkaline earth ions or lanthanum have been reported. ${ }^{[9,11,14-17]}$ In order to unravel the possible differences of lanthanides over calcium in alcohol oxidation reactions we evaluated the ligand $\mathrm{PQQMe}_{2}-1$-aza-15-crown-5 (1) synthesized previously by Itoh and Fukuzumi and the respective $\mathrm{Ca}^{2+}, \mathrm{Ba}^{2+}, \mathrm{La}^{3+}$ and $\mathrm{Lu}^{3+}$ biomimetic complexes. Furthermore, we were interested whether a similar trend in alcohol oxidation activity, where only the early lanthanides are active in MDH enzymes and relevant for bacteria, could also be found for the biomimetic system. In addition, a new synthesis for 1 with higher yields and significantly less steps is reported here and the complexes have been studied with EPR spectroscopy and mass spectrometry methods to gain a deeper insight into the occurring species in solution. 


\section{Results and Discussion}

\section{Ligand Synthesis}

Based on the work of Itoh and Fukuzumi an aza-crown ether was attached to the PQQ scaffold. ${ }^{[9]}$ As precursor $\mathbf{2}$ is only available in low yields via 8-step synthesis, the usage of methylated and selectively hydrolyzed $\mathrm{PQQMe}_{2}(4)$ as a precursor starting from $\mathrm{PQQ}$ was evaluated. ${ }^{[18]}$ We have previously reported the facile isolation of pure PQQ at low-cost from vitamin capsules. ${ }^{[19]}$ The further advantage of $\mathbf{4}$ is that the quinone moiety is already formed, avoiding the oxidation with CAN, and thus introduction of possible cerium traces to the system. Duine et al. described direct methylation of PQQ by $\mathrm{Me}_{2} \mathrm{SO}_{4}$ and $\mathrm{K}_{2} \mathrm{CO}_{3}$ but used a very small scale of only $0.5 \mathrm{mg} \mathrm{PQQ}$ starting material. ${ }^{[20]}$ The method was tested on a $50 \mathrm{mg}$ scale and gave analytically pure $\mathrm{PQQMe}_{3} 3$ as an orange solid in $91 \%$ yield. The scale was successively increased in further reactions and can easily be run in a $500 \mathrm{mg}$ scale, with only a slightly decreased yield of $86 \% \mathrm{PQQMe}_{3}(3)$ was then selectively hydrolyzed, using TFA (Scheme 1). ${ }^{[21]}$ The product PQQMe $e_{2}$ (4) precipitated after addition of water with isolated yields over $90 \%$.<smiles></smiles>

$P Q Q$

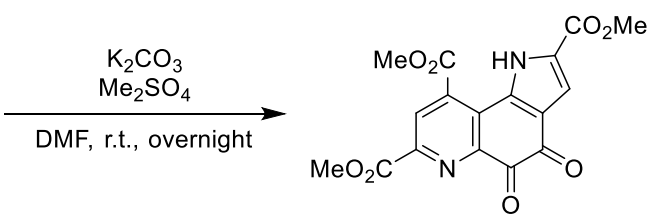

3: $91 \%$
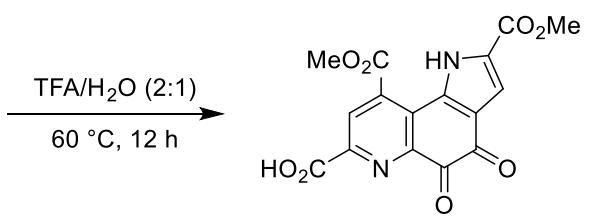

4: $92 \%$

Scheme 1: Conversion of PQQ to $\mathrm{PQQMe}_{3}$ (3) followed by acidic hydrolysis in position C-7 to $\mathrm{PQQMe}_{2}$ (4).

The aza-crown ether precursor was then coupled to 4 using 1,1'-carbonyldiimidazole (CDI) (Scheme 2). This coupling reagent has the advantage of producing only $\mathrm{CO}_{2}$ and imidazole as byproducts which can easily be removed. Nevertheless, the purification of ligand $\mathbf{1}$ showed to be challenging. The implementation of the purification conditions proposed by Itoh and Fukuzumi, ${ }^{[9]}$ which involve column chromatography with silica and a 80:20 EtOAc/EtOH mixture as an eluent, did not give a pure product. Unfortunately, variation of the eluent, including the use of different solvent systems such as $\mathrm{CH}_{2} \mathrm{Cl}_{2} / \mathrm{MeOH}$ and $\mathrm{EtOAc} /$ iso-hexane, did also not lead to the separation of the product from the impurities in our hands. It should be mentioned that the silica exhibited a greenish color after every purification attempt. A sample of the stationary phase was analyzed by CW EPR and showed radical formation, thus this purification method was abandoned (Figure S2). However, experiments have shown that $\mathbf{1}$ could be partially precipitated by addition of water to the crude product. The NMR spectra showed no major impurities except for traces of $\mathrm{H}_{2} \mathrm{O}, \mathrm{DMF}$ and $\mathrm{CH}_{2} \mathrm{Cl}_{2}$ and the elemental analysis was in good agreement with the calculated values. 


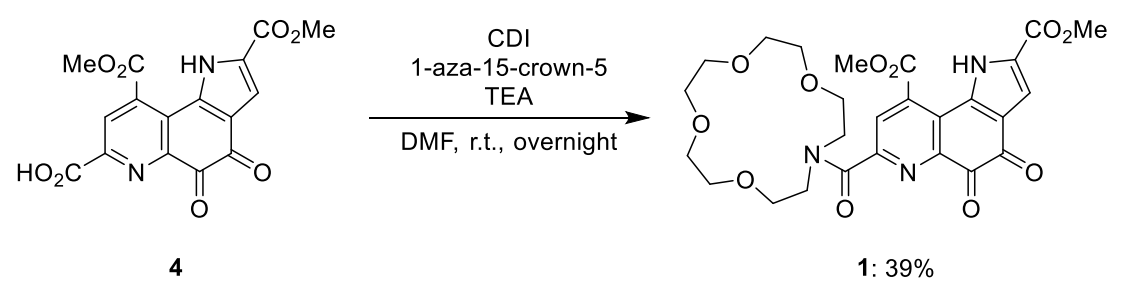

Scheme 2: Amide coupling between $\mathrm{PQQMe}_{2}(4)$ and 1-aza-15-crown-5 using CDI.

Thus, we hope this new and convenient synthesis route with only 3 steps instead of 11 steps to ligand $\mathbf{1}$ (33\% instead of $0.6 \%$ overall yield) will provide fast access to future PQQ-based model complexes of $\mathrm{MDH}$.

\section{Metal Ion Coordination}

Initial efforts were focused on the reproduction of the results from Itoh and Fukuzumi ${ }^{\left[{ }^{[9]}\right.}$ who had used UV-Vis spectroscopy and calcium perchlorate salts, and comparison with the respective lanthanide perchlorate precursors. However, this turned out to be more challenging than anticipated due to highly fluctuating UV-Vis signatures of the PQQ moieties, the hygroscopic nature of the lanthanide perchlorates and thus a fluctuating water and metal content, which made titrations and data evaluation cumbersome. Lumpe and Daumann have previously reported the problems when assigning species in the UV-Vis spectra of PQQ with lanthanide salts as multiple species such as the $\mathrm{PQQ}-\mathrm{H}_{2} \mathrm{O}$ adduct can form with trace amounts of water with their own unique UV-Vis signatures. ${ }^{[19]}$ In addition, all attempts to obtain single crystals of the metal complexes of $\mathbf{1}$ suitable for X-ray analysis were unsuccessful, a circumstance that showed to be a common problem in this and previous studies focusing on the metal interactions with PQQ and PQQ derivatives. ${ }^{[9,19,22]}$ Hence, the interaction of 1 with metal salts was examined using NMR spectroscopy. The metal ion coordination behavior of PQQMe -1 -aza-15-crown-5 (1) in acetonitrile solution was investigated using barium(II) and calcium(II) salts as well the first and last lanthanides from the series, lanthanum(III) and lutetium(III), which are also both diamagnetic (Figure S3).

The addition of solid calcium(II) triflate to the ligand in acetonitrile resulted in an instant color change from orange-yellow to red. In the ${ }^{1} \mathrm{H}$ NMR spectrum, the $\mathrm{H}-8$ proton of the ligand showed a strong downfield shift $\left(\Delta \delta=0.26 \mathrm{ppm}\right.$ ) upon complexation with $\mathrm{Ca}^{2+}$, which was larger than the shift of the $\mathrm{H}-3$ proton $(\Delta \delta=0.08 \mathrm{ppm})$. The values are very close to those reported by Itoh et al. for 1 and calcium perchlorate $\left(\Delta \delta=0.22 \mathrm{ppm}\right.$ and $0.06 \mathrm{ppm}$ respectively). ${ }^{[9]}$ The resonances of the methyl ester protons at the $9^{\prime}$ and $2^{\prime}$ positions were only slightly influenced upon $\mathrm{Ca}^{2+}$ binding $(\Delta \delta=$ $0.05 \mathrm{ppm}$ and $0.03 \mathrm{ppm}$ respectively). The methylene proton resonances of the crown ring on the other hand, showed a clear change in the presence of $\mathrm{Ca}^{2+}$, whereby shifts in both directions, downfield as well as upfield were observed. The tendencies of the chemical shifts in ${ }^{1} \mathrm{H}$ NMR suggest that the interaction between $\mathrm{Ca}^{2+}$ and ligand $\mathbf{1}$ takes place at the crown ether moiety and most probably at the C-5 quinone carbonyl oxygen as well as at the N-6 pyridine nitrogen. Similar shifts were observed upon addition of barium(II) triflate to the ligand solution (Table 1), albeit with a slightly different shift of the crown ether methylene protons (Figure S3).

The addition of $\mathrm{Ln}^{3+}$ salts to the solution of 1 resulted in a color change from orange-yellow to dark red. The obtained ${ }^{1} \mathrm{H}$ NMR spectra showed a very strong metal induced shift of $\mathrm{H}-8\left(\mathrm{La}^{3+}: \Delta \delta=\right.$ 
$0.85 \mathrm{ppm}$ and $\mathrm{Lu}^{3+}: \Delta \delta=1.11 \mathrm{ppm}$ ) and a signal broadening. Similar to the experiment with $\mathrm{Ca}^{2+}$, the $\mathrm{H}-3$ resonance was less shifted in the presence of a $\mathrm{Ln}^{3+}$ ion $(\Delta \delta=0.09 \mathrm{ppm})$. However, a major difference in the ligand ${ }^{1} \mathrm{H}$ NMR spectra upon comparison of the divalent alkaline earth metal ions and the trivalent lanthanides emerged by comparing the changes in the crown ether resonances (Figure S3). The addition of lanthanide(III) triflates resulted only in a small shift of the proton resonance at $3.58 \mathrm{ppm}\left(\mathrm{La}^{3+}: \Delta \delta=0.01 \mathrm{ppm}\right.$ and $\mathrm{Lu}^{3+}: \Delta \delta=0.0 \mathrm{ppm}$, albeit these values are at best estimates as significant signal broadening prevented exact assignment), the alkaline earth metal ion salts on the contrary induced shifts of $0.34 \mathrm{ppm}$ for $\mathrm{Ba}^{2+}$ and $0.41 \mathrm{ppm}$ for $\mathrm{Ca}^{2+}$.

Table 1: Selected ${ }^{1} \mathrm{H}$ NMR resonances (in ppm) of 1 in $\mathrm{CD}_{3} \mathrm{CN}$ and resonance shifts (in ppm) after the addition of different metal triflates.

\begin{tabular}{cccccc}
\hline Position & $\mathbf{1}$ & $\boldsymbol{\Delta} \boldsymbol{\delta}\left(\mathrm{Ba}^{2+}\right)$ & $\boldsymbol{\Delta} \boldsymbol{\delta}\left(\mathrm{Ca}^{2+}\right)$ & $\boldsymbol{\Delta} \boldsymbol{\delta}\left(\mathrm{La}^{3+}\right)$ & $\boldsymbol{\Delta} \boldsymbol{\delta}\left(\mathrm{Lu}^{3+}\right)$ \\
\hline 1 & 12.60 & 0.0 & 0.05 & 0.05 & 0.09 \\
8 & 8.34 & 0.12 & 0.26 & 0.85 & 1.11 \\
3 & 7.31 & 0.06 & 0.08 & 0.09 & 0.09 \\
9'-Me & 4.08 & 0.03 & 0.05 & 0.04 & 0.05 \\
$2 '-M e$ & 3.91 & 0.02 & 0.03 & 0.02 & 0.03 \\
\hline
\end{tabular}

In the ${ }^{13} \mathrm{C}$ NMR spectra, the addition of metal salts to the ligand caused strong resonance shifts and signal disappearance in the case of the lanthanides (Figure S4). However, the carbon resonance at C8 showed a relatively large downfield shift for all four metal ions, while the chemical shift of C-3 was rather small (Table S1). Thus, this observation further supports the assumption for a metal coordination at the correct binding pocket of $\mathrm{PQQ}$.

\section{Impact of the Counterions on the Complex Species}

To study the possible impact of counterions and to gain more insight into the structures and stabilities of the different species present in solution prior to the reaction with alcohols, we performed mass spectrometry and ion mobility experiments in combination with density functional (DFT) calculations.

After mixing ligand 1 and the respective $L n$ salt (nitrate, triflate) in acetonitrile and performing electrospray ionization in positive mode we observed both the $[\mathbf{1}+\mathrm{Ln}+\mathrm{X}]^{2+}$ dication $(\mathrm{Ln}=\mathrm{La}, \mathrm{Lu} ; \mathrm{X}=$ $\left.\mathrm{NO}_{3}, \mathrm{CF}_{3} \mathrm{SO}_{3}\right)$ and $[1+\mathrm{Ln}+2 \mathrm{X}]^{+}$monocation. Interestingly, we cannot detect the complex without counterions, i.e. $[\mathbf{1}+\mathrm{Ln}]^{3+}$, in line with the expected strong electrostatic interaction. To gain more information on the structure and bond strength of the complex, we performed collision induced dissociation (CID) experiments. Therefore, we isolated the dication $[1+L n+X]^{2+}$ in the ion trap of the LTQ Orbitrap-instrument, resonantly excited the oscillatory motion of the ions and collided them with helium background gas in the trap. As shown in the supporting information (Figure S5), we recorded fragment mass spectra as function of the excitation energy (in instrument specific units of normalized collision energy). Independent of counterion (nitrate vs. triflate) and lanthanide (La vs. Lu) we observe $\mathrm{CH}_{3} \mathrm{OH}$-loss as dominant fragmentation channel. This implies that it is easier to break the covalent bond to one of the methoxy-groups in PQQ (plus hydrogen rearrangement) than to 
break the ionic bond to the counterion. While we observe no nitrate loss at all, we observe for the triflate some $\mathrm{CF}_{2} \mathrm{SO}_{3}$-loss as minor channel (with ca. $15 \%$ relative intensity for La and $5 \%$ for Lu) indicating a stronger bond strength of the nitrates, and highlighting the potential different species present during methanol oxidation, depending on the chosen counterion.

To resolve the structure of the complexes we combined DFT-calculations and gas phase ion mobility measurements (IMS). By comparing experimental (via IMS) and calculated (via DFT) collision cross sections (CCS) we can assign the dominant isomers of the $\left[1+\mathrm{Ln}+\mathrm{NO}_{3}\right]$ complexes (in gas phase, as dications), see Figure 2 for $\mathrm{Ln}=\mathrm{La}$ and $\mathrm{Lu}$. We find that in both cases structure $\mathbf{1}\left(\mathrm{Ln}^{3+}\right.$ coordinated by counterion, crown ether moiety as well as the C-5 quinone carbonyl oxygen and the N-6 pyridine nitrogen) is by far the most stable isomer, its calculated CCS agrees with the experimental value within the experimental error of ca. $1 \%$ (See $\mathrm{SI}$ ). The other isomers can be ruled out based on both CCS and relative energies. Furthermore, the Lu-complex has a slightly smaller CCS which is expected due to the lanthanide contraction. For the triflates we find a similar structure (See SI). A more detailed investigation comprising the entire lanthanide series will be subject to a further publication.
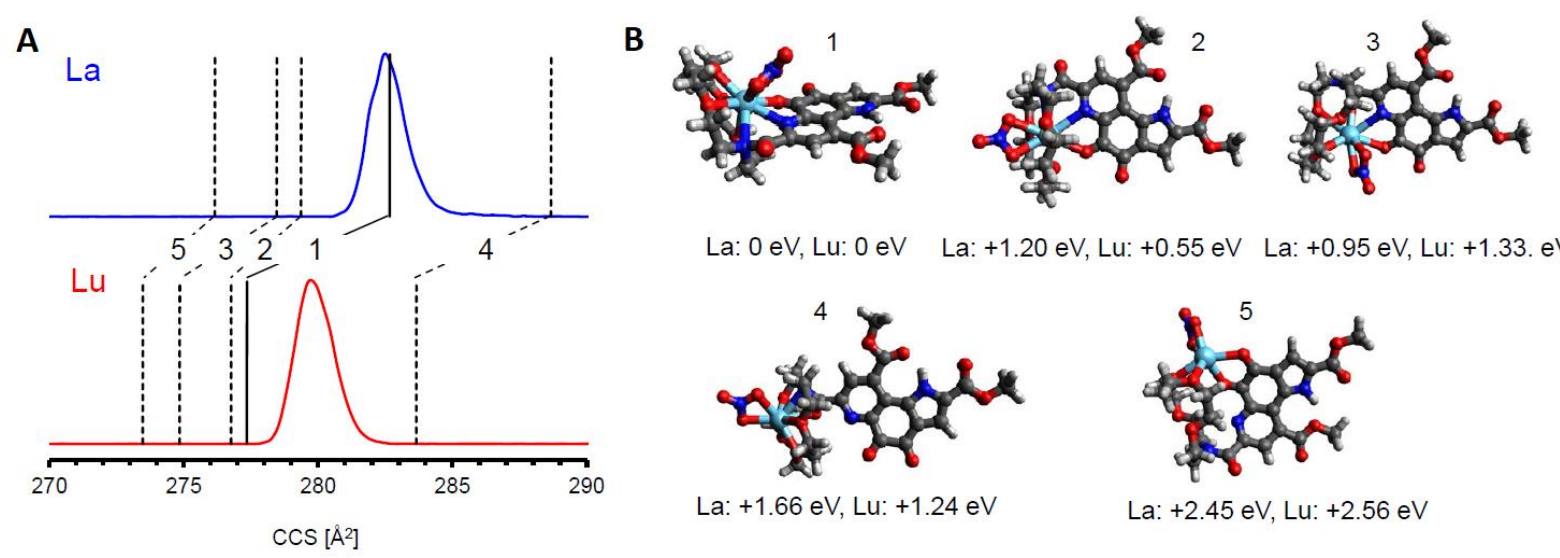

La: 0 eV, Lu: 0 eV La: +1.20 eV, Lu: $+0.55 \mathrm{eV} \quad$ La: $+0.95 \mathrm{eV}$, Lu: $+1.33 . \mathrm{eV}$

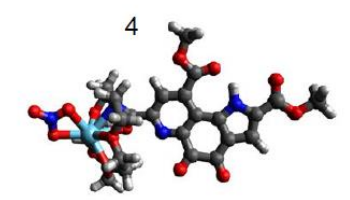

La: $+1.66 \mathrm{eV}, \mathrm{Lu}:+1.24 \mathrm{eV}$

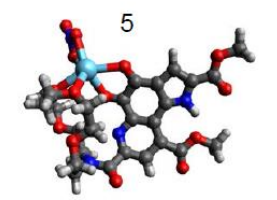

La: $+2.45 \mathrm{eV}$, Lu: $+2.56 \mathrm{eV}$

Figure 2: (A) Mobilograms of $\left[1+\mathrm{La}+\mathrm{NO}_{3}\right]^{2+}$ (blue) and $\left[1+\mathrm{Lu}+\mathrm{NO}_{3}\right]^{2+}($ red $)$ along with calculated CCS for five DFT optimized candidate structures. The CCS of the lowest energy isomer (1) is indicated by a full line, the others by dashed lines. (B) DFToptimized structures along with relative energies. Isomer 1 is clearly favored based on both CCS and relative energies.

\section{Alcohol Oxidation}

In the course of this study, the ability of the model complexes to oxidize alcohols was investigated using ${ }^{1} \mathrm{H}$ NMR, a method that had been previously successfully used by Schelter and coworkers. ${ }^{[11]}$. Previous studies on related systems suggest that alongside the model complex, the addition of a base accelerates the dehydrogenation of alcohols. ${ }^{[9,11,16,17]}$ Hence, the NMR experiments reported in this study were performed with DBU as a base, unless otherwise stated. Furthermore, hexamethyldisiloxane $\left(\mathrm{TMS}_{2} \mathrm{O}\right)$ was used as an internal standard. All reaction mixtures were degassed prior to the addition of the base, to remove air oxygen of the system, which could possibly act as a terminal oxidant.

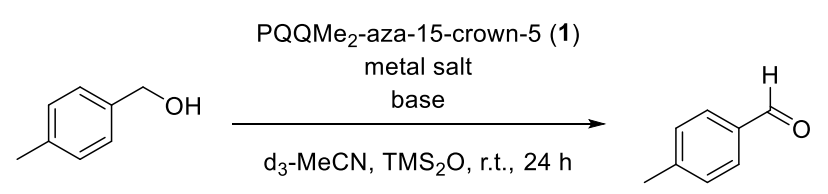

Scheme 3: Dehydrogenation reaction of 4-methyl benzyl alcohol to 4-methyl benzyl aldehyde. 
First, a control reaction with ligand 1, 4-methyl benzyl alcohol and DBU was performed. The reaction progress was monitored over $16 \mathrm{~h}$, however, no traces of substrate turnover could be detected (Figure S6). This underlines the essential role of a Lewis acid for the activation of PQQ and possibly for substrate orientation and activation during alcohol oxidation. The second control reaction further demonstrates the importance of the $\mathrm{PQQ}$ function in the ligand $\mathbf{1}$ for the oxidation of the alcohol: when lanthanum(III) triflate, $4 \mathrm{Me}-\mathrm{PhCH}_{2} \mathrm{OH}$ and $\mathrm{DBU}$ were mixed and monitored over $24 \mathrm{~h}$, no oxidation product 4-methyl benzyl aldehyde was formed, confirming the assumption that both PQQligand and Lewis acid are required for alcohol oxidation (Figure S7).

With both control reactions in hand, the ability of the model system to promote the oxidation of alcohols to aldehydes was examined, using different metal salts. First, the dehydrogenation reaction of 4-methyl benzyl alcohol shown in Scheme 3 was performed using lanthanum(III) triflate and DBU. Here, 4-methyl benzyl aldehyde was obtained in $32 \%$ yield after $24 \mathrm{~h}$ (Figure S8). Subsequently, the progress of the dehydrogenation reaction was examined in the presence of $\mathrm{Lu}^{3+}$. As confirmed by the spectra (Figure S9), the later lanthanide $\mathrm{Lu}^{3+}$ was also able to facilitate the oxidation of the alcohol, however the product yield after $24 \mathrm{~h}$ was only $12 \%$. Later it was shown, that the recorded ${ }^{1} \mathrm{H}$ NMR spectra of the reaction mixture containing $\mathrm{Ca}^{2+}$ showed a higher conversion of the substrate to the corresponding product compared to the $\mathrm{Ln}^{3+}$ (Figure S10). After $24 \mathrm{~h}$, a yield of $58 \%$ was calculated for $4 \mathrm{Me}-\mathrm{PhCHO}$. The ability of the alkaline earth metals to promote the dehydrogenation reaction of the alcohol more effectively than the lanthanides was further confirmed through the measurement of the model system containing $\mathrm{Ba}^{2+}$. Here, a product yield of $67 \%$ was detected after $24 \mathrm{~h}$ (Figure S11).

By comparing the calculated yields of the experiments with all four different metal salts, a clear trend can be observed (Figure 3). The model complexes with calcium(II) and barium(II) were able to accelerate the formation of the product more efficiently in comparison to the two chosen lanthanide ions. Furthermore, it was shown, that the representative of the early lanthanides was also able to promote the conversion of the alcohol faster than the later one, a result that is consistent with the natural MDH enzyme systems. ${ }^{[23]}$ Different factors as for example the stronger Lewis acidity and the smaller ionic radius of lutetium(III) could be considered as a possible explanation for this observation although this might be counterintuitive at first glance. The role of the metal ions here is to act as Lewis acid and activate the C-5 carbon of PQQ as well as possibly facilitating the orientation and activation of the substrate by deprotonation of the alcohol moiety. It is however possible, and this was demonstrated by several computational studies, that $\mathrm{Lu}^{3+}$ is too small to effectively bind to PQQ. ${ }^{[23-25]}$ Moreover, the NMR investigations of the metal interactions with ligand $\mathbf{1}$ described in the previous section suggests a slightly different coordination environment for $\mathrm{Ca}^{2+}$ and $\mathrm{Ba}^{2+}$ in comparison to the $\mathrm{Ln}^{3+}$ ions.

Itoh and Fukuzumi have previously suggested that, assuming that the reaction mechanism goes through the formation of a hemiketal species, the binding of larger ions such as $\mathrm{Ba}^{2+}$ and $\mathrm{Sr}^{2+}$ to $\mathrm{PQQ}$ as well as the pushing effect of the crown ether group from the back can force the added alcohol moiety closer to the C-4 quinone carbonyl oxygen, facilitating the $\alpha$-proton abstraction by the carbonyl oxygen. ${ }^{[9]}$ Here, the results obtained in the experiment with $\mathrm{Lu}^{3+}$, would support this assumption, however, the large difference between the yields of the reactions with $\mathrm{Ca}^{2+}$ and $\mathrm{La}^{3+}$ suggests that additional factors could be involved as well. The most obvious difference is the charge, and it seems plausible that electrostatic effects and possibly attraction other co-ligands (counterions, solvent molecules) could impact binding and conversion of alcohols. After all, the 1-aza-15-crown 
ligand platform does not account for the negative charges of the amino acids. However, especially for Ln-MDH (XoxF-MDH) it has been shown that the additional, negatively charged, aspartate residue in the active site is essential for Ln-binding and substrate turnover. ${ }^{[26]}$

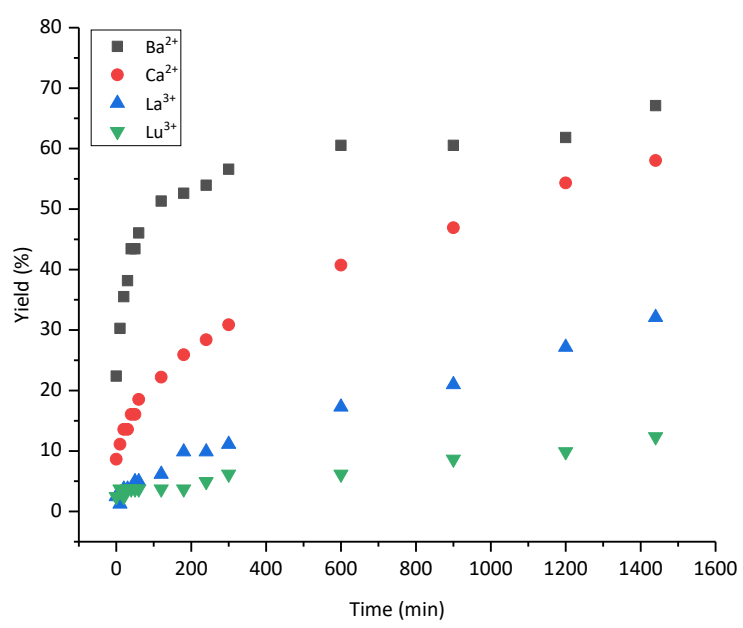

Figure 3: Calculated yields of $4 \mathrm{Me}-\mathrm{PhCHO}$ from the dehydrogenation reactions of $4 \mathrm{Me}-\mathrm{PhCH}_{2} \mathrm{OH}$ by ligand 1 in the presence of barium(II) triflate, calcium(II) triflate, lanthanum(III) triflate and lutetium(III) triflate.

In addition, the impact of the base on the dehydrogenation reaction of 4-methyl benzyl alcohol accelerated by ligand 1 and lanthanum(III) triflate was examined, whereby DBU ( $\mathrm{p} K_{\mathrm{a}}=24.3$ in $\left.\mathrm{CH}_{3} \mathrm{CN}^{[27]}\right)$ was substituted for a different base. As shown in Figure 4, the less basic 2,6-lutidine $\left(\mathrm{p} K_{\mathrm{a}}=\right.$ 14.4 in $\mathrm{CH}_{3} \mathrm{CN}^{[27]}$ ) was used and after $24 \mathrm{~h}$ a $4 \%$ higher product yield than with DBU was achieved (Figure S12). Conducting the experiment with pyridine $\left(\mathrm{p} \mathrm{K}_{\mathrm{a}}=12.5\right.$ in $\left.\mathrm{CH}_{3} \mathrm{CN}^{[27]}\right)$ as a base (Figure S13), a substrate conversion of $43 \%$ was observed, which was $11 \%$ higher than that in the reaction with DBU. Hence, the tendency that weaker bases promote the alcohol oxidation more efficiently within the model system can be observed. Moreover, an additional experiment aimed to examine the reaction outcome in the absence of a base. It was shown, that the alcohol oxidation to the respective aldehyde was still successful (Figure S14), however, only a low yield of $12 \%$ was achieved after $24 \mathrm{~h}$. This observation is close to that made by Schelter and coworkers in a related functional system, ${ }^{[11]}$ and shows that the base accelerates the dehydrogenation reaction but it is not absolutely necessary for a successful product formation. 


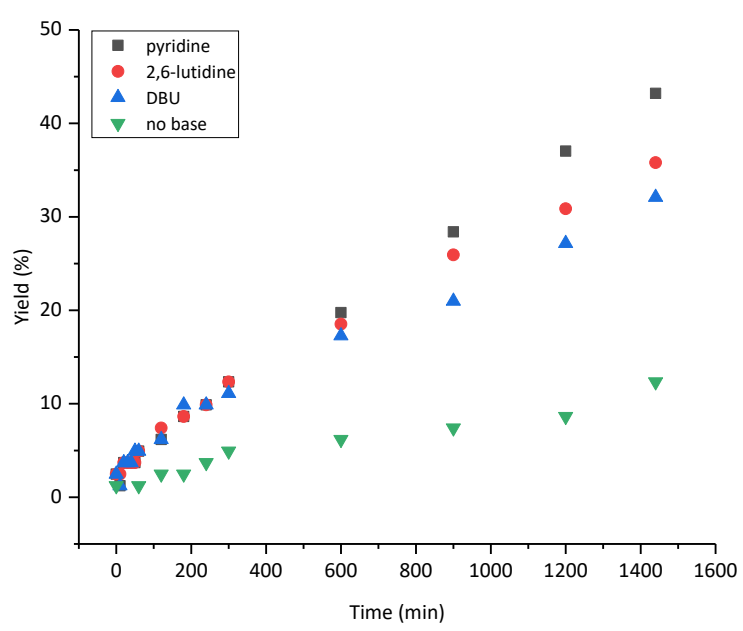

Figure 4: Calculated yields of $4 \mathrm{Me}-\mathrm{PhCHO}$ from the dehydrogenation reactions of $4 \mathrm{Me}-\mathrm{PhCH}_{2} \mathrm{OH}$ by ligand 1 and lanthanum(III) triflate without addition of base and in the presence of 2,6-lutidine, DBU and pyridine.

To test the ability of the model system with a different counterion to accelerate the conversion of alcohols to aldehydes, the dehydrogenation reaction of 4-methyl benzyl alcohol by 1 and DBU was examined in the presence of lanthanum(III) nitrate. The spectra monitoring the reaction progress over $24 \mathrm{~h}$ showed that the oxidation of the alcohol was successful (Figure S15), and the corresponding aldehyde was produced in a yield of $21 \%$. However, it should be noted that the addition of DBU to the reaction mixture led to formation of a precipitation, which may be also the reason for the lower yield of the experiment when comparing it to that performed in the presence of a triflate salt (Figure S16).

\section{EPR Investigation}

Recently, Luo et al. have reported in their preprint that a semi-quinone anionic radical species forms upon coordination of $\mathrm{Lal}_{3}$ with the ortho-quinone $\boldsymbol{o}-\mathbf{Q}$ in acetonitrile. ${ }^{[12]}$ An EPR spectrum of the system showed the presence of an organic radical species with $g=2.003$, which could not be observed in absence of the metal salt. Furthermore the emergence of traces of radicals when PQQ and lanthanide salts are combined has been observed previously by Daumann and coworkers (see note in SI there). ${ }^{[22]}$ Hence, we analyzed the reaction mixtures of the dehydrogenation reactions described in the previous section as well as all reaction components for possible radicals.

Control experiments were undertaken to see if the formation of radical species could be observed without the presence of metal ions and other components considered necessary for substrate turnover. X-band CW EPR spectra were recorded under the given conditions for ligand 1 only, ligand with the addition of DBU and, finally, ligand with the addition of DBU and 4-methyl benzyl alcohol (Figure S17). There was no detectible organic radical for ligand 1 only. However, for the ligand with base and for the ligand with base and alcohol a very small amount of organic radical could be detected, both with an observable g-value of 2.005 (approximately \pm 0.0005 ). It was not possible to calculate the peak-to-peak linewidth either due to the lack of resolution from the low concentrations of radical present. Any radical that could be detected upon addition of base, as well as base and alcohol, demonstrates the general tendency of $\mathrm{PQQ}$ species to readily form a radical. A more detailed explanation for the formation of small quantities of this radical under these conditions is not 
explored in this paper, but the reader might want to refer here to the electrochemistry and EPR investigation of $\mathrm{PQQ}$ trimethyl ester derivatives in the presence and absence of calcium(II) by Itoh and Fukuzumi. ${ }^{[28]}$

CW EPR spectra of ligand 1 bound to $\mathrm{Ca}^{2+}, \mathrm{La}^{3+}$ and $\mathrm{Lu}^{3+}$ with addition of DBU and 4-methyl benzyl alcohol were recorded. The effective g-values and peak-to-peak linewidths were extracted and are given in Table 2. The g-values are consistent with the isotropic g-values obtained for the semiquinone radical species observed in alcohol dehydrogenases in the literature. ${ }^{[29,30]}$ For PQQ trimethyl ester derivatives this value was reported to be around 2.004 in $\mathrm{CH}_{3} \mathrm{CN}$ or $\mathrm{CH}_{2} \mathrm{Cl}_{2}{ }^{[28]}$ The approximated error in the g-value is \pm 0.0005 and in the peak-to-peak linewidth is $\pm 0.05 \mathrm{MHz}$. Peak-to-peak linewidths are fitted based on a Gaussian distribution. The recorded and subsequently simulated spectra are shown below and were normalized in each case (Figure 5). There was significantly less radical signal for the $\mathrm{Lu}^{3+}$ species, as it can be seen from the poor signal-to-noise ratio. The $\mathrm{Eu}^{3+}$ analogue with ligand $\mathbf{1}$, DBU and 4-methyl benzyl alcohol was also measured but did not produce any detectable EPR signal (Figure S18). In addition, the relaxation times $\mathrm{T}_{1}$ and $\mathrm{T}_{2}$ were calculated for $\mathrm{Ca}^{2+}, \mathrm{La}^{3+}$ and $\mathrm{Lu}^{3+}$ and the results are presented in the supporting information (Figure S19 and Table S2).

Table 2: Extracted g-values and peak-to-peak linewidths for different metal ligand 1 species with DBU and 4-methyl benzyl alcohol added.

\begin{tabular}{ccc}
\hline Metal ion & g-value & Linewidth peak-to-peak (MHz) \\
\hline $\mathrm{Ca}^{2+}$ & 2.005 & 0.5 \\
$\mathrm{La}^{3+}$ & 2.003 & 1.4 \\
$\mathrm{Lu}^{3+}$ & 2.003 & 1.6 \\
\hline
\end{tabular}

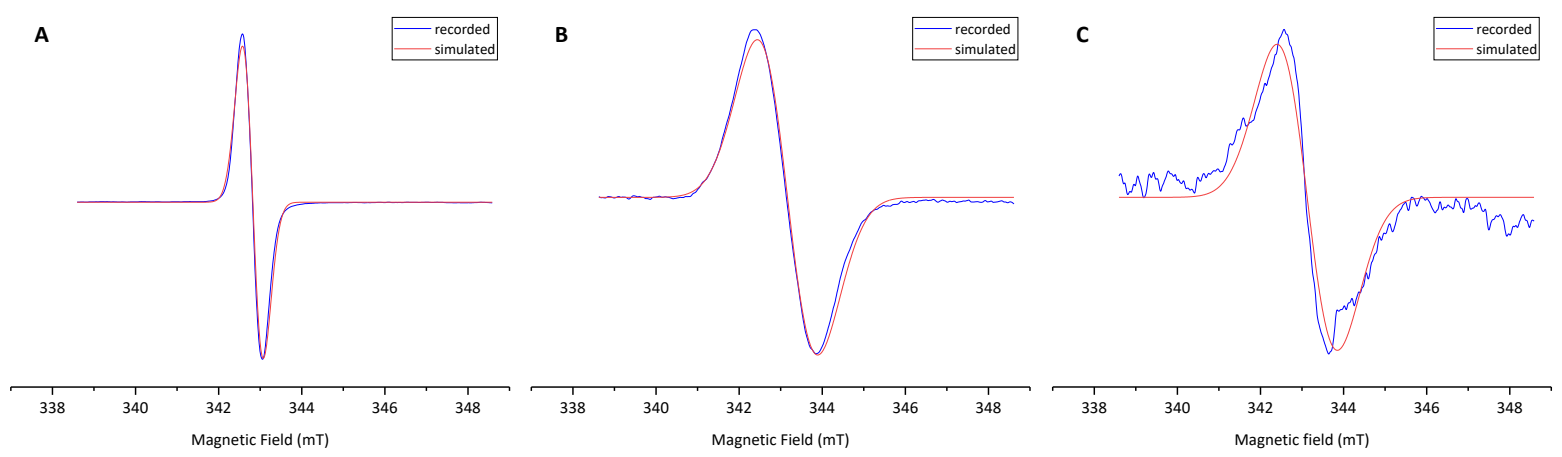

Figure 5: CW EPR spectrum at X-band $(9.5 \mathrm{GHz})$ of ligand 1, 4-methyl benzyl alcohol and DBU in the presence of (A) calcium(II) triflate, (B) lanthanum(III) triflate or (C) lutetium(III) triflate at room temperature. The spectra were normalized in each case.

The data shows that inserting different metal ions significantly affects the peak-to-peak linewidth. There is also a small shift in the g-value depending on whether $\mathrm{Ca}^{2+}$ or a $\mathrm{Ln}^{3+}$ is bound. This potentially suggests that the $\mathrm{Ca}^{2+}$ may be coordinated differently as suggested by the results of NMR experiments but more advanced experimental techniques would be needed to confirm this. For the $\mathrm{Eu}^{3+}$ ligand 1, base and alcohol complex no CW EPR spectrum is observed as $\mathrm{Eu}^{3+}$ may be causing the 
radical to relax too quickly to be measured effectively due to paramagnetic relaxation enhancement. ${ }^{[31-33]}$ Another reason could be that there is additional redox chemistry occurring involving both $\mathrm{Eu}^{2+}$ and $\mathrm{Eu}^{3+}$ species.

Surprisingly, the presence of an alcohol and air made a difference to the amount of radical present. CW EPR spectra were measured at room temperature of $\mathrm{La}^{3+}$, ligand 1 and DBU without 4-methyl benzyl alcohol, with 4-methyl benzyl alcohol and with 4-methyl benzyl alcohol under nitrogen (Figure 6). The relative radical concentration was calculated for each signal. The g-value in each case was 2.003 (approximately \pm 0.0005 ).

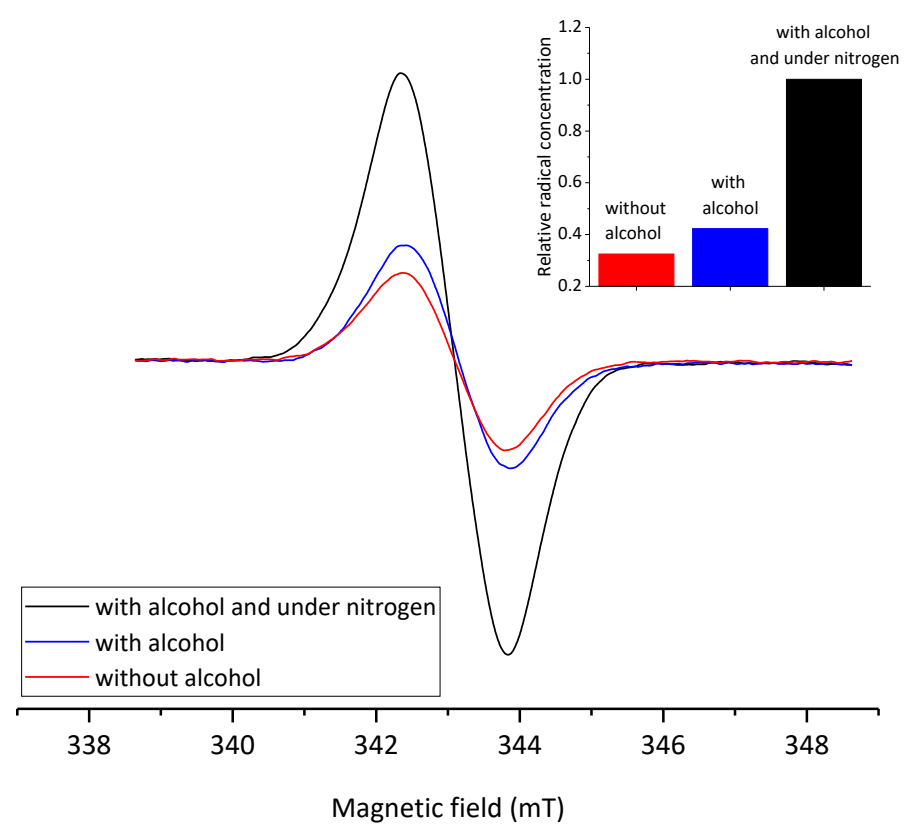

Figure 6: CW EPR spectrum at X-band $(9.5 \mathrm{GHz})$ of ligand 1 and lanthanum(III) triflate with addition of DBU without 4methyl benzyl alcohol, with 4-methyl benzyl alcohol and with 4-methyl benzyl alcohol under nitrogen at room temperature. Inset: relative radical concentration.

There is a slightly larger amount of radical present when alcohol is added compared to when no alcohol is added. This could suggest that there may be radicals formed as part of the mechanism for the catalytic reaction. However, the organic radical is still present even without alcohol, again showing that PQQ species tend to form radicals readily when exposed to various conditions. Remarkably, there is a much greater proportion of the radical present when the CW EPR is performed under nitrogen i.e. in absence of air. There may be more radical present simply because it is not being quenched by diradical oxygen or because oxygen might be involved in re-oxidation of (partially) reduced semiquinone/quinol forms of PQQ. This highlights the importance to run control reactions both under inert atmosphere as well as in air or at least consider the impact of radical formation and oxygen on these types of reactions. 


\section{Summary}

We report here the first investigation of biomimetics bearing lanthanides $\left(\mathrm{La}^{3+}\right.$ and $\left.\mathrm{Lu}^{3+}\right)$ compared to $\mathrm{Ca}^{2+}$ and $\mathrm{Ba}^{2+}$. When using the previously reported PQQMe $2-1$-aza-15-crown-5 1 ligand platform, that does not account for the negative charges present on MxaF- or XoxF-MDH, the alkaline earth model complexes present, in fact, higher activity and yields in the alcohol dehydrogenation reaction. This highlights the importance of fine-tuning ligand environments in biomimetics. Further, we observed that the larger ions were more active than the smaller counterparts $\left(\mathrm{Ba}^{2+}>\mathrm{Ca}^{2+}\right.$ and $\left.\mathrm{La}^{3+}>\mathrm{Lu}^{3+}\right)$ and this behavior mimics the findings in natural systems, where Ba-MDH had been shown to have a significantly lower activation energy barrier and the early lanthanides were shown to be more effective in turning over substrate in $\mathrm{Ln}-\mathrm{MDH}$. We further show that both counterions and base have some impact on the substrate conversion outcome, and using CID measurements we showed that nitrate counterions are, as expected, more tightly bound than the triflate ions. By comparing ion mobility measurements and density functional calculations, we gained insight into the speciation and structure of the complexes, and we believe such methods are of great importance in the design of future biomimetics as the well-defined speciation of Ln-complexes both in the gas and solution phase is currently an understudied, however emerging area of interest. ${ }^{[34,35]} \mathrm{A}$ PQQ-based radical was observed under substrate turnover conditions and this warrants further investigation, possibly with pulsed EPR methods and comparison to the natural systems, where a semiquinone radical has been denoted as a stable intermediate. Taken together we hope that our study will help guide the design, synthesis and characterization of MDH biomimetics, and ultimately lead to a better understanding of $\mathrm{MDH}$ enzymes in the future.

\section{Experimental Section}

\section{Synthesis of $\mathrm{PQQMe}_{3}(3)$}

Based on procedures, described by Duine et al. ${ }^{[20]}$ and Urakami et al. ${ }^{[36]}$ in a dry and nitrogen flushed Schlenk flask, PQQ (50.0 mg, $0.151 \mathrm{mmol}, 1.0$ equiv.) was dissolved in dry DMF ( $2 \mathrm{~mL}$ ). Potassium carbonate $(0.523 \mathrm{mg}, 3.79 \mathrm{mmol}, 25.0$ equiv.), which was previously dried under high vacuum at $650^{\circ} \mathrm{C}$ (heat-gun), was given to the PQQ solution under nitrogen counter-flow. Dimethyl sulfate $(1.55 \mathrm{~mL}, 1.33 \mathrm{~g} / \mathrm{mL}, 16.3 \mathrm{mmol}, 108$ equiv.) was added and the mixture was stirred at room temperature and under nitrogen overnight, to give a bright orange suspension the next day. In order to completely remove $\mathrm{K}_{2} \mathrm{CO}_{3}$ residues and to quench the excess of $\mathrm{Me}_{2} \mathrm{SO}_{4}, \mathrm{HCl}(8 \mathrm{~mL} 2 \mathrm{M}$ and $1 \mathrm{~mL}$ conc.) was added and the mixture was further stirred for $5 \mathrm{~h}$. The orange precipitate was filtered off, and the residue was washed with water and dried under high vacuum to give pure $\mathrm{PQQMe}_{3}$ (3) (51 mg, 0.137 mmol, 91\%). ${ }^{1} \mathrm{H}-\mathrm{NMR}$ (400 MHz, DMSO-d 6 ): $\delta / \mathrm{ppm}=12.51(\mathrm{~s}, 1 \mathrm{H}, 1), 8.56(\mathrm{~s}, 1 \mathrm{H}, 8)$, $7.29(\mathrm{~d}, \mathrm{~J}=2.1 \mathrm{~Hz}, 1 \mathrm{H}, 3), 4.05$ (s, 3H, 9'-Me), 3.96 (s, 3H, 7'-Me), 3.89 (s, 3H, 2'-Me). ${ }^{13} \mathrm{C}-\mathrm{NMR}(100$

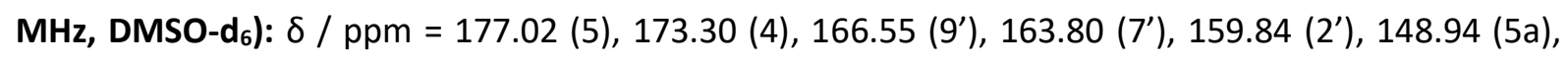
145.73 (7), 134.16 (9), 133.54 (1a), 128.48 (8), 126.58 (9a), 126.49 (2/3a), 124.96 (2/3a), 113.84 (3), 54.20 (9'-Me), 52.95 (7'-Me), 52.36 (2'-Me). HRMS (ESI): $\mathrm{m} / z$ calc. for $\left[\mathrm{C}_{17} \mathrm{H}_{13} \mathrm{~N}_{2} \mathrm{O}_{8}\right]^{+}: 373.0666$, found: 373.0665. IR (Diamond-ATR, neat): $\tilde{v} / \mathrm{cm}^{-1}=3126$ (w), 1717 (s), 1679 (s), 1552 (w), 1495 (m), 1429 (s), 1345 (w), 1266 (s), 1200 (s), 1171 (s), 1115 (s), 1075 (s), 995 (s), 953 (s), 923 (s), 900 (s), $834(\mathrm{~s})$, 
$807(\mathrm{~s}), 783(\mathrm{~s}), 769(\mathrm{~s}), 754(\mathrm{~s}), 733(\mathrm{~s}), 720(\mathrm{~s}), 689(\mathrm{~m}), 672(\mathrm{~m})$. Elemental Analysis (CHN): \% calc. for $\left[\mathrm{C}_{17} \mathrm{H}_{12} \mathrm{~N}_{2} \mathrm{O}_{13}\right]$ : $\mathrm{C} 54.85 ; \mathrm{H} 3.25 ; \mathrm{N} 7.52$, found: C 54.59; H 3.36; N 7.48.

\section{Synthesis of PQQMe 2 (4)}

$\mathrm{PQQMe}_{3}$ (3) $(50 \mathrm{mg}, 0.134 \mathrm{mmol})$ was given in a $10 \mathrm{~mL}$ round bottom flask and a 1:2 mixture of $\mathrm{H}_{2} \mathrm{O} /$ TFA ( $2 \mathrm{~mL}$ ) was added. The dark red solution was stirred at $60^{\circ} \mathrm{C}$ for $36 \mathrm{~h}$. After cooling down to room temperature, $\mathrm{H}_{2} \mathrm{O}(5 \mathrm{~mL})$ was added, which caused immediate precipitation of a dark red solid. The precipitate was filtered off, washed with water, dried first at $100^{\circ} \mathrm{C}$ for several hours and then under high vacuum overnight, to afford $44 \mathrm{mg}(0.123 \mathrm{mmol}, 92 \%)$ of a light brown powder. ${ }^{1} \mathbf{H}-\mathbf{N M R}$ (400 MHz, DMSO-d $\left.\mathrm{d}_{6}\right): \delta / \mathrm{ppm}=12.52(\mathrm{~s}, 1 \mathrm{H}, 1), 8.56(\mathrm{~s}, 1 \mathrm{H}, 8), 7.28(\mathrm{~d}, \mathrm{~J}=1.4 \mathrm{~Hz}, 1 \mathrm{H}, 3), 4.05(\mathrm{~s}, 3 \mathrm{H}$, 9'-Me), 3.89 (s, 3H, 2'-Me). ${ }^{13}$ C-NMR (100 MHz, DMSO-d 6 ): $\delta$ / ppm = 177.26 (5), 173.33 (4), 166.73 (9'), 164.78 (7'), 159.85 (2'), 148.87 (5a), 147.00 (7), 134.07 (9), 133.74 (1a), 128.49 (8), 126.38 (2/3a), 126.29 (9a), 124.82 (2/3a), 113.84 (3), 54.19 (9'-Me), 52.36 (2'-Me). Assignments of 5, 4, 5a and 7 based on literature-known PQQ-shifts. HRMS (ESI): $\mathrm{m} / z$ calc. for $\left[\mathrm{C}_{16} \mathrm{H}_{11} \mathrm{~N}_{2} \mathrm{O}_{8}\right]^{+}: 359.0512$, found: 359.0510. IR (Diamond-ATR, neat): $\tilde{v} / \mathrm{cm}^{-1}=3443$ (w), 3101 (w), 1762 (w), 1706 (s), 1675 (s), 1551 (w), $1495(\mathrm{~m}), 1435$ (m), 1362 (w), 1287 (s), 1240 (s), 1209 (s), 1156 (s), 1133 (s), 1058 (w), 994 (m), $960(\mathrm{~m}), 921(\mathrm{~m}), 870(\mathrm{~m}), 768(\mathrm{~m}), 692(\mathrm{~m})$. Elemental Analysis (CHN): \% calc. for $\left[\mathrm{C}_{16} \mathrm{H}_{10} \mathrm{~N}_{2} \mathrm{O}_{8} \cdot 1.2 \mathrm{H}_{2} \mathrm{O}\right]: \mathrm{C} 50.59 ; \mathrm{H} 3.29 ; \mathrm{N} 7.37$, found: $\mathrm{C} 50.54 ; \mathrm{H} 3.21 ; \mathrm{N} 7.53$.

\section{Synthesis of PQQMe -1 -aza-15-crown-5 (1):}

In a dry and nitrogen flushed Schlenk-flask, equipped with a magnetic stirring bar and a septum, $\mathrm{PQQMe}_{2}$ (4) (101 mg, $0.284 \mathrm{mmol}, 1.0$ equiv.) and CDI (93.0 mg, $0.573 \mathrm{mmol}, 2.0$ equiv.) were dissolved in dry DMF (4 mL) and were stirred for $30 \mathrm{~min}$ at room temperature. In a second dry and nitrogen flushed flask, 1-aza-15-crown-5 $(62.2 \mathrm{mg}, 0.284 \mathrm{mmol}, 1.0$ equiv.) was dissolved in dry DMF $(2 \mathrm{~mL})$ and TEA $(0.08 \mathrm{~mL}, 0.726 \mathrm{~g} / \mathrm{mL}, 0.573 \mathrm{mmol}, 2.0$ equiv.) was added. Subsequently, the amine solution was added to the solution of the activated acid and the reaction mixture was stirred at room temperature overnight. After completion of the reaction, the solvent was removed in vacuo. The crude product was suspended in water $(20 \mathrm{~mL})$ and extracted with $\mathrm{CH}_{2} \mathrm{Cl}_{2}(3 \times 20 \mathrm{~mL})$. The combined organic layers were washed with $1 \mathrm{M} \mathrm{HCl}(20 \mathrm{~mL})$ and water $(20 \mathrm{~mL})$. The solvent was evaporated and the residue was suspended in water $(10 \mathrm{~mL})$. The suspension was centrifuged $(5 \mathrm{~min}$ at $4500 \mathrm{rpm}$ ) and the supernatant was removed. The residue was vortex mixed with water, centrifuged again and lyophilized to give PQQMe 2 -1-aza-15-crown-5 (1) $(62.5 \mathrm{mg}, 0.112 \mathrm{mmol}, 39 \%)$ as a brown-red solid. ${ }^{1} \mathrm{H}-\mathrm{NMR}\left(400 \mathrm{MHz}, \mathrm{CD}_{3} \mathrm{CN}\right): \delta / \mathrm{ppm}=12.60(\mathrm{~s}, 1 \mathrm{H}, 1), 8.34(\mathrm{~s}, 1 \mathrm{H}, 8), 7.31(\mathrm{~s}, 1 \mathrm{H}, 3), 4.08\left(\mathrm{~s}, 3 \mathrm{H}, 9^{\prime}-\right.$ $\mathrm{Me}), 3.91$ (s, 3H, 2'-Me), 3.83-3.77 (m, 5H, C1-C10), 3.72-3.71 (m, 2H, C1-C10), 3.62-3.55 (m, 15H, C1C10). ${ }^{13} \mathrm{C}-\mathrm{NMR}\left(100 \mathrm{MHz}, \mathrm{CD}_{3} \mathrm{CN}\right): \delta / \mathrm{ppm}=180.4$ (5), 174.4 (4), 168.9 (9'), $168.0\left(7^{\prime}\right), 161.2$ (2'), 155.0 (7), 147.8 (5a) ,135.6 (1a), 135.3 (9a), 130.4 (8), 128.2 (2), 126.4 (9), 125.4 (3a), 115.0 (3), 71.6 (C1-C10), 71.4 (C1-C10), 70.9 (C1-C10), 70.8 (C1-C10), 70.7 (C1-C10), 69.1 (C1-C10), 55.3 (9'-Me), 53.1 (2'-Me), 52.2 (C1-C10), 50.2 (C1-C10). Assignments based on 2D-NMR HMBC- and HMQC- spectra. HRMS (ESI): $\mathrm{m} / z$ calc. for $\left[\mathrm{C}_{26} \mathrm{H}_{28} \mathrm{~N}_{3} \mathrm{O}_{11}\right]^{-}: 558.1729$, found: 558.1728. IR (Diamond-ATR, neat): $\tilde{v}$ / $\mathrm{cm}^{-1}=2920(\mathrm{~m}), 2851(\mathrm{~m}), 2360(\mathrm{w}), 1713(\mathrm{~s}), 1679(\mathrm{~s}), 1622(\mathrm{~s}), 1575(\mathrm{w}), 1558(\mathrm{w}), 1496(\mathrm{~m}), 1475$ $(\mathrm{m}), 1436(\mathrm{~s}), 1404(\mathrm{~m}), 1346(\mathrm{w}), 1283(\mathrm{~m}), 1253(\mathrm{~m}), 1227(\mathrm{~s}), 1204(\mathrm{~s}), 1118(\mathrm{~s}), 1070(\mathrm{~m}), 1002$ $(\mathrm{m}), 983(\mathrm{~m}), 936(\mathrm{~m}), 840(\mathrm{~m}), 796(\mathrm{~m}), 771(\mathrm{~m}), 757(\mathrm{~m}), 737(\mathrm{~m}), 722(\mathrm{~m}), 707(\mathrm{~m}), 699(\mathrm{~m})$.

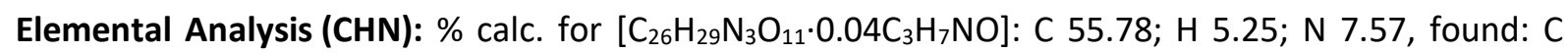
55.75; H 5.34; N 7.49. 


\section{NMR Experiments}

${ }^{1} \mathrm{H}$ NMR and ${ }^{13} \mathrm{C}$ NMR spectra were recorded at room temperature with Bruker Avance III spectrometer operating at $400 \mathrm{MHz}$ for proton nuclei and $100 \mathrm{MHz}$ for carbon nuclei. ${ }^{1} \mathrm{H}$-chemical shifts are reported in units of ppm relative to $\mathrm{CD}_{3} \mathrm{CN}\left(\delta_{\mathrm{H}}=1.94\right)$ or DMSO-d $\mathrm{d}_{6}\left(\delta_{\mathrm{H}}=2.50\right) .{ }^{13} \mathrm{C}$-chemical shifts are given in units of ppm relative to $\mathrm{CD}_{3} \mathrm{CN}\left(\delta_{\mathrm{C}}=1.32\right)$ or DMSO- $\mathrm{d}_{6}\left(\delta_{\mathrm{C}}=39.52\right)$. The software used for data processing was MNova Version 12.0.1. Two-dimensional correlation spectroscopy (COSY), heterobinuclear multiple quantum correlation (HMQC) and heterobinuclear multiple bond connectivity $(\mathrm{HMBC})$ experiments were used to assign each resonance in the spectra.

Dehydrogenation Reactions. PQQMe 2 -1-aza-15-crown-5 1 (6.5 mM, 1.0 equiv.) was placed in a sealable NMR tube with a septum and was dissolved in $\mathrm{CD}_{3} \mathrm{CN}(0.55 \mathrm{~mL}) . \mathrm{TMS}_{2} \mathrm{O}$ (1.0 equiv.) was added and a ${ }^{1} \mathrm{H}$ NMR spectrum was recorded. Then, a metal salt (2.0 equiv.) was added and a second spectrum was recorded. After addition of 4-methyl benzyl alcohol (4.0 equiv.), a third ${ }^{1} \mathrm{H}$ NMR was measured. Subsequently the reaction mixture was degassed by using an ultrasonic bath, high vacuum and nitrogen. Finally, degassed base (2.0 equiv.) was added, the tube was shaken to ensure complete mixing and a ${ }^{1} \mathrm{H}$ NMR spectrum was recorded as quickly as possible. The reaction was then monitored by recording spectra every ten minutes (for $1 \mathrm{~h}$ ), then every one hour (for $4 \mathrm{~h}$ ), then every five hours (for $15 \mathrm{~h}$ ). The final spectrum was recorded after $24 \mathrm{~h}$ after the start of the reaction. The metal salts used were $\mathrm{Ba}(\mathrm{OTf})_{2}, \mathrm{Ca}(\mathrm{OTf})_{2} \cdot \mathrm{H}_{2} \mathrm{O}, \mathrm{Ln}(\mathrm{OTf})_{3} \cdot 3 \mathrm{H}_{2} \mathrm{O}(\mathrm{Ln}=\mathrm{La}$, $\mathrm{Eu}$ and $\mathrm{Lu})$ and $\mathrm{La}\left(\mathrm{NO}_{3}\right)_{3} \cdot 6 \mathrm{H}_{2} \mathrm{O}$ and the bases used were $\mathrm{DBU}, 2,6$-lutidine and pyridine.

The reactions involving the absence of one of the components were performed following the same experimental procedure by skipping the corresponding addition step. The reaction monitoring was then performed by recording spectra in bigger time intervals (see supporting information).

\section{EPR Experiments}

EPR measurements were performed using a BRUKER EMXNano X-band $(9.5 \mathrm{GHz})$ spectrometer at room temperature. All 1D CW EPR experiments were conducted using a microwave power of $1.0 \mathrm{~mW}$. Modulation amplitudes and frequencies of $0.01 \mathrm{mT}$ and $100 \mathrm{kHz}$ were used, respectively. A time constant of $1.28 \mathrm{~ms}$ and a sweep time of 5 minutes were also used.

CW spectra were processed using MATLAB ${ }^{\circ}$ and EasySpin software. ${ }^{[37]}$ To take into account the rapid tumbling of the solutions which were measured, the CW EPR spectra were processed using the garlic function. ${ }^{[37]}$ After spectra were processed using the software, parameters were extracted by fitting the spectra obtained using a non-linear least squares regression model (Nelder/Mead downhill simplex algorithm) where the overall RMSD value for the entire system was minimized to as close to zero as possible. Using the parameters extracted from the recorded spectra, simulated spectra could be produced and compared to the recorded spectra.

The concentration of ligand $\mathbf{1}$ was $25 \mathrm{mM}$ in acetonitrile. Depending on the nature of the experiment, the amount of metal salt if added was 2.0 equiv., the amount of 4-methyl benzyl alcohol if added was 4.0 equiv. and the amount of DBU if added was 2.0 equiv. (Figure S20). The metal salts used were $\mathrm{Ca}(\mathrm{OTf})_{2} \cdot \mathrm{H}_{2} \mathrm{O}$ and $\mathrm{Ln}(\mathrm{OTf})_{3} \cdot 3 \mathrm{H}_{2} \mathrm{O}(\mathrm{Ln}=\mathrm{La}$, Eu and Lu).

Relative radical concentration could be obtained by measuring CW EPR spectra, and calculating the double integral of the differential spectra which was recorded as this value is proportional to the 
amount of radical in the system for a given species. Relative ratios where then taken of these raw values.

\section{Mass Spectrometry, Ion Mobility Experiments and DFT Calculations}

The mass spectroscopy and collision induced dissociation experiments were performed with a LTQ Orbitrap XL (Thermo Scientific) mass spectrometer with helium in the ion trap. The ions were generated with electrospray ionisation in positive mode using acetonitrile as solvent. Typical spray conditions were: needle voltage $3 \mathrm{kV}$, capillary temperature $50{ }^{\circ} \mathrm{C}$. The concentrations of ligand $\mathbf{1}$ and the metal salts were each $0.5 \mathrm{mM}$ in acetonitrile. The metal salts used were $\operatorname{Ln}(\mathrm{OTf})_{3} .3 \mathrm{H}_{2} \mathrm{O}$ and $\mathrm{Ln}\left(\mathrm{NO}_{3}\right)_{3} \cdot 6 \mathrm{H}_{2} \mathrm{O}(\mathrm{Ln}=\mathrm{La}, \mathrm{Lu})$.

The gas phase ion mobility studies were performed on a timsTOF (Bruker) with nitrogen as buffer gas. The experimental collision CCS were compared with predictions based on DFT (density functional theory) combined with trajectory calculations. The DFT calculations were performed with the TURBOMOLE package ${ }^{[38]}$ with the TPSS functional ${ }^{[39]}$ and def2-SVP basis set ${ }^{[40]}$. Based on the DFT optimized structures theoretical CCS are calculated with the trajectory method as implemented in the IMOS 1.09 package ${ }^{[41,42]}$ using Mulliken partial charges.

\section{Acknowledgements}

The authors would like to acknowledge Brigitte Breitenstein for NMR measurements. The authors would like to thank Marianne Friemert for her preliminary UV-Vis investigations. L.J.D., H.L. and V.A.V. would like to acknowledge a grant from the Deutsche Forschungsgemeinschaft (DFG)-392552271 as well as support from the L.M.U. P.W., E.S. and A.S. thank Manfred Kappes for discussions and access to the Bruker timsTOF at the Institute of Nanotechnology. The Orbitrap@IPC/KIT used for this work was funded by DFG under INST 42/644-1 FUGG.

\section{References}

[1] R. R. Crichton, Biological Inorganic Chemistry - A New Introduction to Molecular Structure and Function, Elsevier, Oxford, 2012.

[2] N. Picone, H. J. Op den Camp, Curr. Opin. Chem. Biol. 2019, 49, 39-44.

[3] T. Cheisson, E. J. Schelter, Science 2019, 363, 489-493.

[4] L. Chistoserdova, Mol. Microbiol. 2019, 111, 1127-1131.

[5] L. J. Daumann, Angew. Chemie Int. Ed. 2019, 58, 12795-12802.

[6] J. A. Cotruvo, ACS Cent. Sci. 2019, 5, 1496-1506.

[7] J. T. Keltjens, A. Pol, J. Reimann, H. J. M. Op den Camp, Appl. Microbiol. Biotechnol. 2014, 98, 6163-6183.

[8] E. F. Pettersen, T. D. Goddard, C. C. Huang, G. S. Couch, D. M. Greenblatt, E. C. Meng, T. E. Ferrin, J. Comput. Chem. 2004, 25, 1605-1612.

[9] S. Itoh, H. Kawakami, S. Fukuzumi, J. Mol. Catal. B Enzym. 2000, 8, 85-94. 
[10] D. R. Houck, J. L. Hanners, C. J. Unkefer, M. A. G. van Kleef, J. A. Duine, in PQQ Quinoproteins, Springer Netherlands, Dordrecht, 1989, pp. 177-185.

[11] A. McSkimming, T. Cheisson, P. J. Carroll, E. J. Schelter, J. Am. Chem. Soc. 2018, 140, 12231226.

[12] R. Zhang, L. Zhang, M.-T. Zhang, S. Luo, 2020, DOI 10.26434/chemrxiv.13299785.v1.

[13] W. L. Dorfner, P. J. Carroll, E. J. Schelter, Org. Lett. 2015, 17, 1850-1853.

[14] S. Itoh, M. Ogino, Y. Fukui, H. Murao, M. Komatsu, Y. Ohshiro, T. Inoue, Y. Kai, N. Kasai, J. Am. Chem. Soc. 1993, 115, 9960-9967.

[15] S. Itoh, X. Huang, H. Kawakami, M. Komatsu, Y. Ohshiro, S. Fukuzumi, J. Chem. Soc., Chem. Commun. 1995, 2077-2078.

[16] S. Itoh, H. Kawakami, S. Fukuzumi, J. Am. Chem. Soc. 1997, 119, 439-440.

[17] S. Itoh, H. Kawakami, S. Fukuzumi, Biochemistry 1998, 37, 6562-6571.

[18] H. Lumpe, Lanthanide Dependent Methanol Dehydrogenases: A Theoretical and Biomimetic Investigation, Ludwig Maximilian University of Munich, 2019.

[19] H. Lumpe, L. J. Daumann, Inorg. Chem. 2019, 58, 8432-8441.

[20] J. A. Duine, J. Frank Jzn, P. E. J. Verwiel, Eur. J. Biochem. 1980, 108, 187-192.

[21] S. Itoh, J. Kato, T. Inoue, Y. Kitamura, M. Komatsu, Y. Ohshiro, Synthesis 1987, 1067-1071.

[22] H. Lumpe, A. Menke, C. Haisch, P. Mayer, A. Kabelitz, K. V. Yusenko, A. Guilherme Buzanich, T. Block, R. Pöttgen, F. Emmerling, et al., Chem. Eur. J. 2020, 26, 10133-10139.

[23] H. Lumpe, A. Pol, H. J. M. Op den Camp, L. J. Daumann, Dalton Trans. 2018, 47, 10463-10472.

[24] S. Tsushima, Phys. Chem. Chem. Phys 2019, 21, 21979-21983.

[25] M. Prejanò, N. Russo, T. Marino, Chem. Eur. J. 2020, 26, 11334-11339.

[26] N. M. Good, M. Fellner, K. Demirer, J. Hu, R. P. Hausinger, N. C. Martinez-Gomez, J. Biol. Chem. 2020, 295, 8272-8284.

[27] I. Kaljurand, A. Kütt, L. Sooväli, T. Rodima, V. Mäemets, I. Leito, I. A. Koppel, J. Org. Chem. 2005, 70, 1019-1028.

[28] S. Itoh, H. Kawakami, S. Fukuzumi, J. Am. Chem. Soc. 1998, 120, 7271-7277.

[29] S. Gómez-Manzo, A. A. González-Valdez, J. Oria-Hernández, H. Reyes-Vivas, R. ArreguínEspinosa, P. M. H. Kroneck, M. E. Sosa-Torres, J. E. Escamilla, FEMS Microbiol. Lett. 2012, 328, 106-113.

[30] C. W. M. Kay, B. Mennenga, H. Görisch, R. Bittl, FEBS Lett. 2004, 564, 69-72.

[31] T. Sarna, J. S. Hyde, H. M. Swartz, Science 1976, 192, 1132-1134.

[32] S. W. Meinhardt, T. Ohnishi, Biochim. Biophys. Acta 1992, 1100, 67-74.

[33] W. E. Antholine, J. S. Hyde, H. M. Swartz, J. Magn. Reson. 1978, 29, 517-522.

[34] P. R. Nawrocki, N. Kofod, M. Juelsholt, K. M. $\varnothing$. Jensen, T. J. Sørensen, Phys. Chem. Chem. Phys. 2020, 22, 12794-12805.

[35] L. G. Nielsen, T. J. Sørensen, Inorg. Chem. 2020, 59, 94-105.

[36] T. Urakami, A. Tanaka, K. Yamaguchi, T. Tsuji, E. Niki, Biofactors 1995, 5, 139-146.

[37] S. Stoll, A. Schweiger, J. Magn. Reson. 2006, 178, 42-55. 
[38] F. Furche, R. Ahlrichs, C. Hättig, W. Klopper, M. Sierka, F. T. Weigend, WIREs Comput. Mol. Sci. 2014, 4, 91-100.

[39] J. Tao, J. P. Perdew, V. N. Staroverov, G. E. Scuseria, Phys. Rev. Lett. 2003, 91, 146401.

[40] F. Weigend, R. Ahlrichs, Phys. Chem. Chem. Phys. 2005, 7, 3297-3305.

[41] C. Larriba, C. J. Hogan Jr, J. Phys. Chem. A 2013, 117, 3887-3901.

[42] C. Larriba, C. J. Hogan Jr, J. Comput. Phys. 2013, 251, 344-363. 